\title{
Cyclic Responding by Pigeons on the Peak Timing Procedure
}

\author{
Kim Kirkpatrick-Steger, Stuart S. Miller, Catherine A. Betti, and Edward A. Wasserman \\ University of Iowa
}

\begin{abstract}
The present experiment examined whether discrimination learning shapes the single-peaked response distributions usually obtained with the peak procedure. Two sources of learning in pigeons were disclosed: learning to respond near the time of reinforcement on fixed interval (FI) trials and learning to withhold responding once the FI duration had elapsed on peak interval (PI) trials. Pigeons also produced a highly unexpected second peak in responding on nonreinforced PI trials at 3 times the FI duration. Follow-up experiments showed that a 1:4 FI:PI duration ratio supported double peaks, but only 1 peak was obtained with a 1:8 FI:PI duration ratio. Finally, 4 peaks could be observed on extra-long PI trials under a 1:4:8 FI:PI:PI ratio procedure. The multiple-peaked response distributions are an unprecedented finding that present a major challenge to any theory of time perception.
\end{abstract}

In the 25 years since Catania $(1970$, p. 11) first proposed the peak procedure as a means of gaining further insight into the discriminative control of operant behavior by the passage of time, it has become a very popular method of studying the temporal control of operant responding (e.g., Gibbon \& Church, 1984; Roberts, 1981). In this procedure, longer duration peak interval (PI) trials are interpolated into sessions that also comprise standard fixed interval (FI) trials. Both FI and PI trials are associated with the same external signal. The PI trials usually end in nonreinforcement, and they provide a shrewd way to measure any changes in responding beyond the time of reinforcement on FI trials.

It is commonly found that responding on PI trials rises up to the time of reinforcement on FI trials; thereafter, responding falls, with this descent sometimes mirroring the initial ascent (Church, Miller, Meck, \& Gibbon, 1991; Roberts, 1981). Despite the large number of studies that have used this method of behavioral measurement, we still know very little about the origin of temporal control in the peak procedure. This empirical gap results from investigators' concentrating on final patterns of responding in the peak procedure to the relative neglect of the possible acquisition of these response patterns.

Our project began as an effort to explore the origin of responding on PI trials. We asked: Is the typical temporal response distribution seen on PI trials after extended peak

Kim Kirkpatrick-Steger, Stuart S. Miller, Catherine A. Betti, and Edward A. Wasserman, Department of Psychology, University of Iowa.

This research was conducted in conjunction with the honors theses of Catherine A. Betti (1994) and Stuart S. Miller (1995) at the University of Iowa. Special thanks go to Sue Astley, Brent Finger, and Sonya Ulrich for their help in designing and conducting this research.

Correspondence concerning this article should be addressed to Kim Kirkpatrick-Steger, who is now at the Department of Psychology, Brown University, Box 1853, Providence, Rhode Island 02912. Electronic mail may be sent via Internet to kkirk@brownvm.brown.edu. trial training observable from the initial introduction of PI trials, or is that distribution the product of prolonged peak trial training? Our investigative strategies were straightforward. First, we recorded responding on PI trials from their first presentation after subjects had been given prior training on FI trials only. We thus could monitor responding on PI trials from their very first presentation until they were presented 600 times over a 60-day period. Second, we compared the time course of responding on PI trials in two groups of subjects: those whose PI trials ended in responseindependent nonreinforcement (the standard method used in the timing field) and those whose PI trials ended in response-dependent reinforcement (a nonstandard method that nonetheless gives the experimenter the same opportunity to measure responding on probe trials that extend beyond the duration of FI training trials). With these two strategies we succeeded in showing that (a) the typical PI trial distributions commonly reported in the timing literature are clearly shaped by peak trial training and (b) the end-oftrial consequence on PI trials has very little effect on responding up to the time of reinforcement on FI trials, but it does affect responding later in the PI trials.

Beyond these possibly unsurprising experimental findings, we were greatly surprised to find that two peaks in the response distributions could be observed on peak trials that ended in nonreinforcement. The source of these double peaks led us to examine the role of three temporal factors: (a) the specific duration of the FI, (b) the specific duration of the PI, and (c) the duration of the FI relative to the duration of the PI. Our evidence suggests that a 1:4 FI:PI duration ratio is highly conducive to obtaining this unexpected result. Finally, we were able to observe four peaks when two PI durations were randomly intermixed with the FI in daily sessions: one at the (highly effective) 1:4 FI:PI duration ratio and the other at the (generally ineffective) $1: 8$ FI:PI duration ratio.

Multiple cycles of responding and nonresponding on peak trials suggest the operation of an intrinsic timing oscillator that can free run in the absence of synchronizing external stimuli. Understanding the operation of such a behavioral 
oscillator presents a strong challenge to current theories of timing.

\section{Experiment 1a}

The typical peak procedure experiment largely ignores the possibility that the final temporal response distributions may differ from the initial response patterns. Yet exposure to the peak trials themselves may alter the shape of the resulting temporal response distribution. Previous studies have shown that pigeons can discriminate two intervals associated with one external signal (Cheng \& Roberts, 1989; Leak \& Gibbon, 1995; Ulrich, 1993); so, it is possible that they may also learn to discriminate between the normal FI trials and the longer PI trials, even though both are associated with the same signal. In order to document any learning about the duration of the FI and PI trials, one needs to isolate FI training from PI testing.

We are aware of only three reports in which exposure to the FI was given before the introduction of PI trials. Two (Cheng \& Roberts, 1991; Cheng, Westwood, \& Crystal, 1993) gave only a small number (five or fewer) of initial sessions with the FI alone, too few to produce a strong scalloped response pattern. In the third, Roberts, Cheng, and Cohen (1989) trained pigeons to respond to different 15 -s and 30-s signals until strong scallops developed by the end of 20 sessions. The birds were then given 25 sessions that interspersed 90-s peak trials with the FI 15-s and FI 30-s schedules. However, these authors did not document any changes in the response distributions over the course of peak trial testing.

Therefore, in the present study we examined the development of responding under the peak procedure by isolating two possible sources of learning - timing of the FI trials and timing of the PI trials-to see if exposure to peak trials affected the temporal control of operant behavior. First, the FI scallop was allowed to develop during a prolonged training stage in which FI 30 -s trials were given alone. Then, PI trials were abruptly introduced; these trials were $120 \mathrm{~s}$ long and entailed either experimental extinction or response-dependent reinforcement. At issue was whether a response peak at or near $30 \mathrm{~s}$ would be observable in each group from the inception of peak trial testing and whether the within-trial time course of responding on PI trials would change with prolonged peak trial testing. Also at issue was whether reinforced or nonreinforced PI trials would be equally effective in measuring the temporal control of operant behavior.

\section{Method}

\section{Subjects}

Eight feral pigeons served as subjects. They were naive to the peak procedure, but they had participated in previous studies on visual perception. The birds were maintained at $85 \%$ of their free-feeding weights by the delivery of mixed grain during the experiment. They were individually housed with an ad-libitum supply of water and grit. Cages were located in a colony room that was on a 14-10-hr light-dark cycle, with lights on at 7:00 a.m. and off at 9:00 p.m.

\section{Apparatus}

The experimental sessions were conducted in four identical operant chambers. Three Plexiglas response keys $(2.5 \mathrm{~cm}$ in diameter) were located in a row on the front panel. The keys were spaced $5.7 \mathrm{~cm}$ apart and were located $4 \mathrm{~cm}$ below the houselight and $12 \mathrm{~cm}$ above the food hopper. Only the center key was used: it was lit red by an in-line projector containing a small bulb. The hopper opening was $4.9 \times 5.5 \mathrm{~cm}$, and it was illuminated during reinforcement. The duration of hopper access could be varied from 0.75 to $5.00 \mathrm{~s}$ to maintain the birds at $85 \%$ of their free-feeding weights. Externally mounted fans provided constant ventilation. and audio speakers fed continuous white noise into the experimental room. Data were collected by a Hewlett Packard 386 PC with the Med-PC software system (Tatham \& Zurn, 1989).

\section{Procedure}

FI 30-s training. During training, the birds received 30-36 daily sessions comprising 40 trials of a discrete-trial FI 30-s schedule. The FI was timed by the duration of the red keylight, and pecks to the lit key were recorded in 1-s bins. The first peck after the 30-s interval turned off the keylight and delivered food. A 5-s intertrial interval (ITI), beginning at the offset of the grain hopper, separated trials. The houselight was turned off during hopper activation, but was on at all other times, including the period of the ITI.

FI 30/PI 120 testing. After FI 30-s training, the birds were divided into two groups $(n=4)$. Ten PI 120-s trials were intermixed with 40 FI 30 -s trials. For both groups, the first 10 trials of each session presented the FI $30-8$ schedule alone. The last 40 trials were arranged in 10 four-trial blocks; each four-trial block contained three FI 30-s trials and one PI 120-s trial, randomly distributed. The red keylight was on for the duration of both the $30-\mathrm{s}$ and 120 -s intervals. Subjects in the reinforcement condition $(30+1$ $120+$ ) received 120 -s trials ending in food reinforcement; the first peck after $120 \mathrm{~s}$ turned off the keylight and the houselight and operated the food hopper for the same duration as on FI trials. Subjects in the nonreinforcement condition $(30+/ 120-)$ did not receive food on 120 -s trials, nor did they have to peck the key to end the PI; the end of the PI was signaled by turning off both the keylight and the houselight. The houselight stayed off for the duration of hopper access on nonreinforced PI trials as well as on reinforced FI and PI trials, but it was relit during the ITI and the following trial. Because the hopper access duration could vary from 0.75 to $5.00 \mathrm{~s}$ for a given bird, depending on variations in its weight, the time during which the houselight was off could also vary over the same range. Moreover, because the hopper access duration varied both across birds and across sessions for a given bird, the duration of the houselight-off period also varied in the same manner. Turning off the houselight at the end of the reinforced FI and PI trials ought to have enhanced the salience of the lighted food hopper; turning off the houselight at the end of the nonreinforced PI trials equated the stimulus contexts of the reinforcement and nonreinforcement conditions and ought to have effectively signaled the end of the PI. FI 30/PI 120 testing lasted for 60 days. 


\section{Data Analysis}

Beyond recording the incidence of responding in 1-s bins on each peak trial, we conducted break-run-break (BRB) analyses in order to characterize individual PI trials (Cheng \& Westwood, 1993). The responses were now collapsed into $2-s$ bins. The onset of each PI trial was considered to be the beginning of the first break. The first 2-s bin that began a series of at least three consecutive bins containing any responses was designated as the start of a run (R). Similarly, the first 2 -s bin that began a series of at least three consecutive bins containing no responses was designated as the start of a break (B). Trials could therefore be coded according to the number of breaks and runs in responding that they contained.

\section{Results and Discussion}

\section{FI 30-s Training}

Figure 1 displays the momentary rate of key pecking on FI 30-s trials during the final 6-day block of FI 30-s training for all 8 birds. The response rate was calculated in pecks per minute and displayed in 1-s bins. By the end of FI 30-s
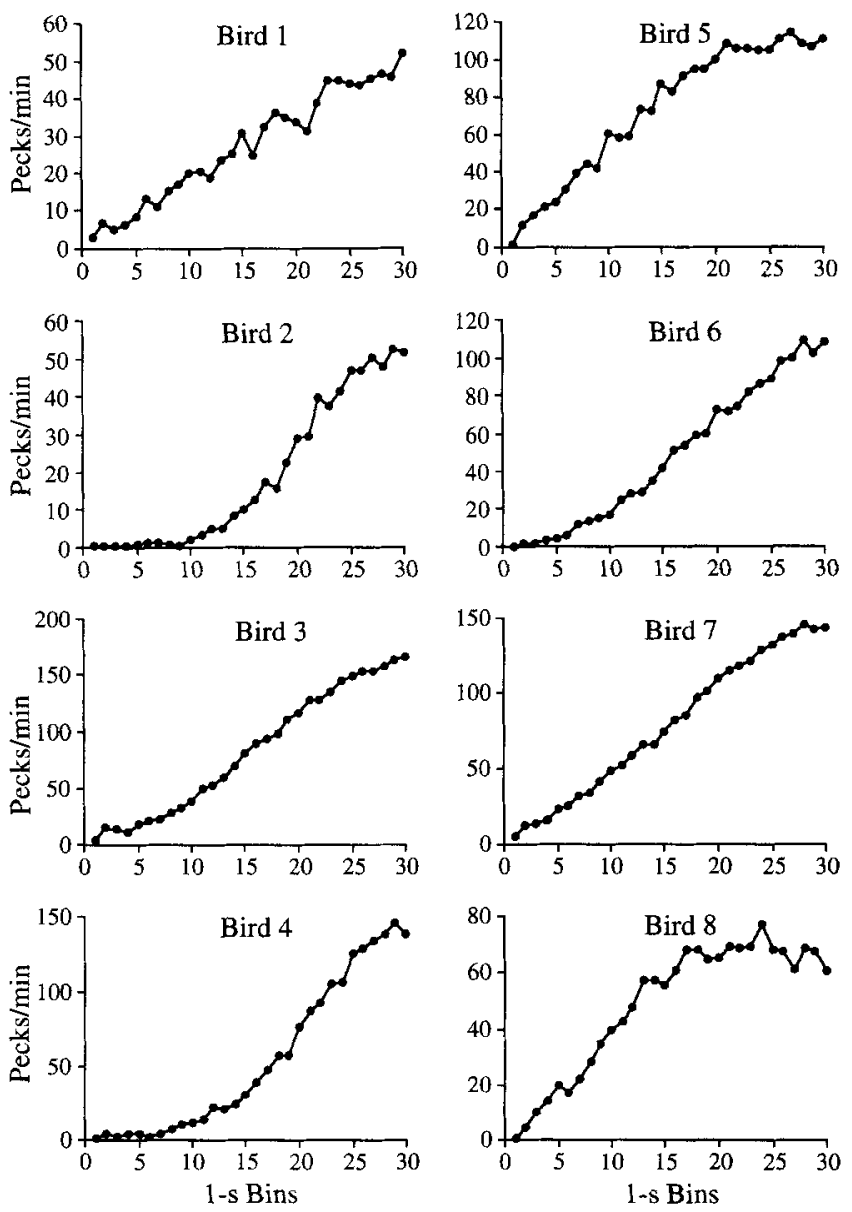

Figure 1. Response rate in successive 1-s bins for the final 6-day block of 30-s fixed interval training in Experiment 1a, displayed for individual birds. training, all subjects showed a rapid rise in responding, with the highest response rates recorded during the last $10 \mathrm{~s}$ of the 30-s FI.

\section{FI 30/PI 120 Testing}

Figure 2 displays the temporal response distributions on PI 120-s trials in 1-s bins, during FI 30/PI 120 testing. Each panel of the figure presents the mean of the 4 pigeons in Group $30+/ 120+(\operatorname{Birds} 1,2,3$, and 4 ) and the 4 pigeons in Group 30+/120- (Birds 5, 6, 7, and 8). The data from Trial 1, Day 1, Days 1-6, Days 25-30, and Days 55-60 are shown from top to bottom. The response rate was calculated in pecks per minute. A curve-fitting operation was conducted on Trial 1 to smooth the data for presentation purposes. Both Trial 1 curves were fit with a fifth-order polynomial; the $R^{2}$ of the fit was .73 for Group $30+/ 120+$ and .51 for Group 30+/120-.

In general, the response distributions on Trial 1 for subjects in both groups revealed a rapid rise in responding, peaking near $40 \mathrm{~s}$. After the peak was reached, responding slowly fell toward the end of the trial at $120 \mathrm{~s}$, but the fitted curves never dropped below 60 pecks $/ \mathrm{min}$. Over the course of continued exposure to the PI 120-s trials, the response distributions underwent considerable change. On Day 1, the character of the response distributions was similar to that of Trial 1 in both groups; the response rates rapidly rose to a peak between 30 and $40 \mathrm{~s}$ and then gradually fell over the course of the interval. However, by the end of the first 6-day block, a narrower peak had emerged that was similar for both groups. The peak time moved even closer to $30 \mathrm{~s}$, and a sharper drop in responding appeared after the peak; however, the tail of both distributions remained high throughout the remainder of the interval. By Days 25-30, a largely symmetrical and narrow peak had emerged around $30 \mathrm{~s}$. The response distributions remained unchanged through Days 55-60. Because the sharp peak at $30 \mathrm{~s}$ did not exist at the start of testing, the response distributions must have been shaped by prolonged exposure to peak trials, revealing that learning had occurred-learning that, if it did not create, it certainly sharpened the peaked response distributions.

The role of learning is further underscored by the decidedly different temporal response distributions observed on reinforced and nonreinforced PI trials from Days 25-60. Responding in Group $30+/ 120+$ rose until $30 \mathrm{~s}$, dropped until $60 \mathrm{~s}$, and then slowly rose again until the end of the trial. The birds in Group 30+/120- also produced a response peak at $30 \mathrm{~s}$, but they produced a second peak at 90 $\mathrm{s}$ that then sharply fell by $120 \mathrm{~s}$. Thus, although the reinforcement outcome on peak trials altered the timing of the PI 120-s interval, the effects were clearest in the second half of the PI. All of these results suggest that a symmetrical single peak is not an inevitable result of extended exposure to the FI schedule of reinforcement.

The double peaks observed in Group 30+/120- were highly surprising given that the usual outcome of the peak procedure with nonreinforced PI trials is a single peak 

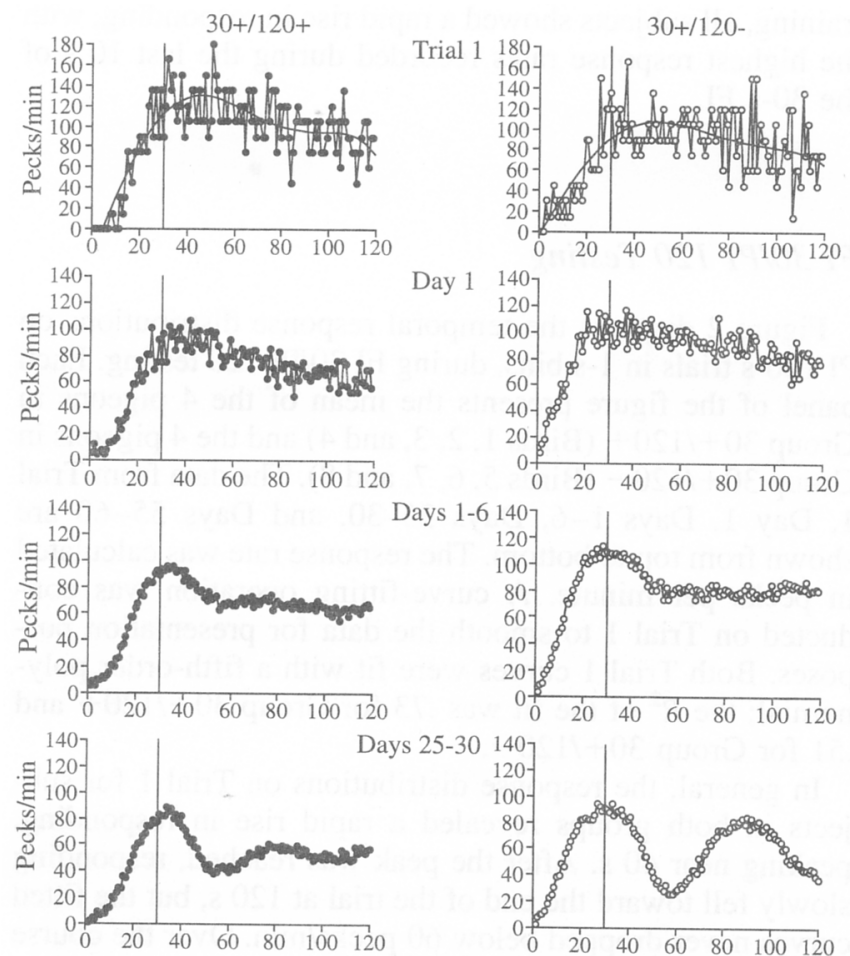

Days 25-30 140
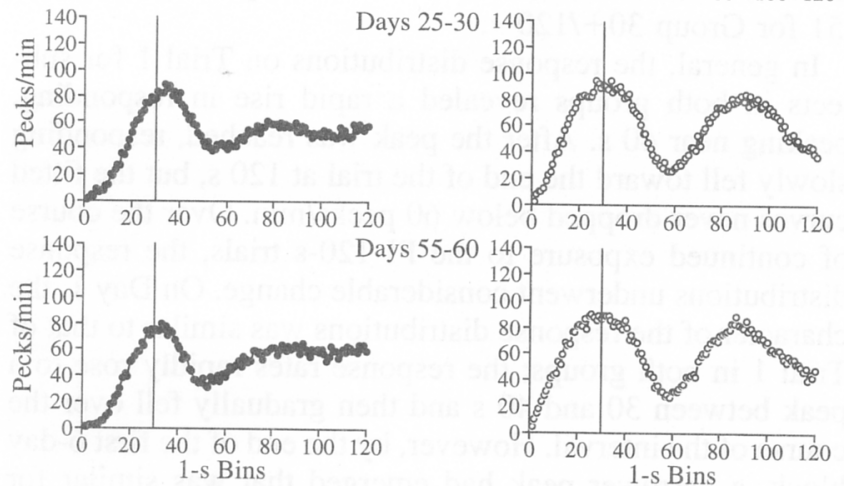

Days 55-60 140

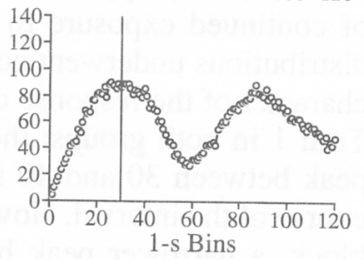

Figure 2. Response rate in successive 1-s bins for 30-s fixed interval/120-s peak interval testing on 120 -s peak trials. Data are shown for the reinforcement and nonreinforcement groups on Trial 1, Day 1, Days 1-6, Days 25-30, and Days 55-60 of peak interval testing in Experiment 1 a.

around the time of reinforcement on FI trials. Because no food was available at the end of the PI and there were no changes in the red keylight that timed the PI, the many "wasted" responses that yielded the second peak were doubly unexpected. We conducted an analysis of individual PI trials to see if the second peak might somehow have been due to an infelicitous averaging artifact.

A BRB analysis was conducted to characterize the 60 individual PI trials from Days 55-60 for each bird in Groups $30+/ 120+$ and $30+/ 120-$ (see Data Analysis for details). Table 1 presents the results of the BRB analysis expressed as a percentage of each individual pigeon's total trials that conformed to a given pattern. Although the categories of patterns in the table always begin with a break, a small percentage of the peak trials $(0.8 \%$ of all trials in the reinforcement condition and $8.3 \%$ of all trials in the nonreinforcement condition) did actually begin with a run. Because the main point of the analysis was to determine the number of cycles in a trial, those trials that began with a run were grouped with those trials that began with a break (e.g.,
BRBR and RBR were grouped together and classified as BRBR).

As can be seen in Table 1, very different patterns of breaking and running were produced by the two groups. In Group $30+/ 120+$, two response patterns predominated - BR and BRBR-that accounted for $91.4 \%$ of all trials: the overall modal pattern was BR. In Group $30+/ 120-$, $89.1 \%$ of all trials fell into three categories: BRBR, BRBRB, and BRBRBR, with an overall modal pattern of BRBRB. An analysis of variance with the factors of group and pattern revealed a significant interaction, $F(6,42)=$ $21.0, p<.001$. Tukey post hoc analyses revealed that Group $30+/ 120+$ produced more BR patterns than did Group $30+/ 120-$, whereas Group $30+/ 120--$ produced more BRBRB patterns than did Group $30+1120+(p)<$ $.05)$.

The BRBRB pattern is consistent with a double-peaked response distribution in which the two peaks would be characterized by two runs with breaks on either side. If the birds in Group 30+/120 - had produced only a single peak (the normal outcome of the peak procedure), then there should have been a large proportion of trials falling within the BRB category. In fact, the BRB trials constituted an extremely small percentage $(2.5 \%)$ of the total trials for the nonreinforcement group.

The source of the second peak in Group 30+/120 - is far from obvious. The BRB analyses showed that it clearly was not due to an averaging artifact. Because there were no changes in the red keylight during the PI 120-s trials, the second peak must have been "internally" generated. It is possible that the specific temporal values of FI and PI trials. their unique combination, or their ratio to one another were important factors. In later experiments we examined these possibilities.

\section{Experiment $\mathrm{lb}$}

Prior research with the peak procedure has revealed only a single peak at the time of reinforcement. Therefore, some aspect of our particular design must have engendered the unusual double-peaked distribution in Group $30+/ 120-$. Of the published research in which the peak procedure has been used, only one study by Church, Meck, and Gibbon (1994) incorporated a 1:4 FI:PI duration ratio in which the PI trial was a fixed length. There, rats were trained with a $60+/ 240-$ procedure; however, only responding during the first half of the 240-s interval was reported.

In Experiment $1 \mathrm{~b}$ we sought to determine if the particular FI/PI combination of $30 \mathrm{~s}$ and $120 \mathrm{~s}$ had produced the double peaks. Three additional phases were completed with Group 30+1120 - from Experiment la. First, the FI was changed to $15 \mathrm{~s}$, but the PI remained at $120 \mathrm{~s}(15+/ 120-)$. Then, the schedule was returned to $30+/ 120-$. Finally, the PI was lengthened to $240 \mathrm{~s}$, but the FI remained at $30 \mathrm{~s}$ $(30+/ 240-)$. 
Table 1

Results of a Break-Run-Break Analysis for Days 55-60 of FI 30/PI 120 Training

\begin{tabular}{|c|c|c|c|c|c|c|c|c|c|c|}
\hline \multirow[b]{2}{*}{ Pattern } & \multicolumn{5}{|c|}{ Group $30+/ 120+$} & \multicolumn{5}{|c|}{ Group $30+/ 120-$} \\
\hline & Bird 1 & Bird 2 & Bird 3 & Bird 4 & $M$ & Bird 5 & Bird 6 & Bird 7 & Bird 8 & $M$ \\
\hline BR & 62.4 & 45.0 & 86.7 & 38.3 & 58.1 & 1.7 & 0.0 & 11.7 & 0.0 & $3.3^{*}$ \\
\hline BRB & 0.0 & 0.0 & 0.0 & 1.7 & 0.4 & 6.7 & 3.3 & 0.0 & 0.0 & 2.5 \\
\hline BRBR & 33.3 & 45.0 & 8.3 & 46.7 & 33.3 & 38.3 & 33.3 & 36.7 & 25.0 & 33.3 \\
\hline BRBRB & 1.7 & 0.0 & 1.7 & 3.3 & 1.7 & 51.7 & 38.3 & 31.7 & 50.0 & $42.9 *$ \\
\hline BRBRBR & 0.0 & 10.0 & 1.7 & 10.0 & 5.4 & 1.7 & 18.3 & 11.7 & 20.0 & 12.9 \\
\hline BRBRBRB & 0.0 & 0.0 & 1.7 & 0.0 & 0.4 & 0.0 & 3.3 & 3.3 & 3.3 & 2.5 \\
\hline Other & 1.7 & 0.0 & 0.0 & 0.0 & 0.4 & 0.0 & 3.3 & 5.0 & 1.7 & 2.5 \\
\hline
\end{tabular}

Note. The data are expressed as the percentage of total trials conforming to a given pattern for both individual birds and for the mean of the 4 birds in each group. BR = break-run, BRB = break-run-break, etc.; Other = those trials that failed to conform to any of the listed patterns; FI = fixed interval; $\mathrm{PI}=$ peak interval.

$* p<.05$.

\section{Method}

\section{Subjects}

The subjects were the same 4 pigeons from the nonreinforcement condition in Experiment 1a. Their housing conditions remained the same.

\section{Apparatus}

The daily sessions were conducted in the same four operant chambers used in Experiment la.

\section{Procedure}

$15+/ 120-$ testing. The Group $30+/ 120$ - birds from Experiment la were shifted directly from $30+/ 120$ - testing to $15+/$ 120 - testing. During $15+/ 120-$ testing, the $30-\mathrm{s}$ FI was shifted to a 15-s FI; the 120-s PI remained the same. The first 10 trials of each session involved the FI 15-s schedule, whereas the last 40 trials were arranged in 10 four-trial blocks that consisted of three FI 15-s trials and one PI 120-s trial. The trial arrangement, 5-s fixed ITI, and general experimental procedures were the same as in $30+/ 120-$ testing in Experiment 1a. Testing continued for 60 days.

$30+/ 120$ - testing. In an attempt to recapture the doublepeaked distribution that had disappeared during $15+/ 120-$ testing, we returned the FI 15-s schedule to an FI 30-s schedule. All other facets of the procedure were the same as in $30+/ 120-$ testing in Experiment 1a. Testing lasted for 60 days.

$30+/ 240-$ testing. During $30+/ 240$ - testing, the 120 -s PI was lengthened to $240 \mathrm{~s}$. All other facets of the procedure were the same as in $30+/ 120-$ testing in Experiment 1a. Testing lasted for 36 days.

\section{Results and Discussion}

The top right panel of Figure 3 shows the terminal response profile of the $15+/ 120-$ phase, in which the birds were shifted from an FI 30-s to an FI 15-s schedule but the PI was kept at $120 \mathrm{~s}$. In contrast to performance on the preceding $30+/ 120-$ schedule shown in the top left panel of Figure 3, there was no hint of a second response peak. Rather, the birds produced a pronounced peak near $15 \mathrm{~s}$, a nadir near $30 \mathrm{~s}$, and a gradual rise in responding toward $120 \mathrm{~s}$.

When the schedule was shifted back to the original $30+1$ 120 - procedure shown in the bottom left panel of Figure 3, the response distribution generally returned to its original form shown in the top left panel of Figure 3. The birds again produced two peaks, one at the time of reinforcement ( $30 \mathrm{~s})$ and another at three times that duration $(90 \mathrm{~s})$. Thus, double peaks could be recaptured, even after exposure to a different FI/PI mixture that did not support a second peak.

When the PI was shifted from 120 s to 240 s $(30+/ 240-)$, shown in the bottom right panel of Figure 3, the response distribution yielded only one peak at the time of reinforce-
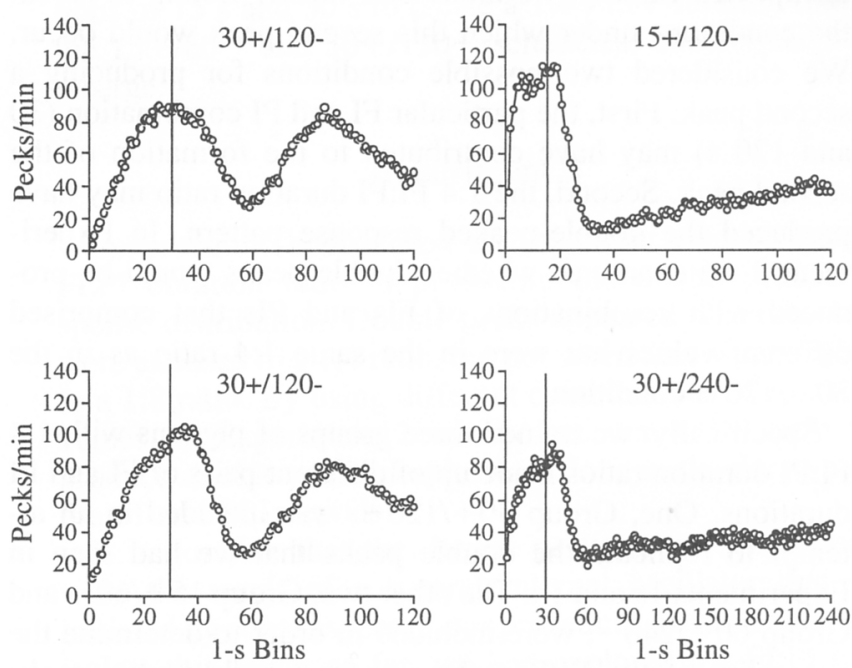

Figure 3. Response rate in successive 1-s bins for the final 6-day block of training in the $15+/ 120-, 30+/ 120-$, and $30+/ 240-$ conditions. The top left panel displays the final block of training from the $30+/ 120-$ condition of Experiment 1a. The top right, bottom left, and bottom right panels display the final blocks of training from the $15+/ 120-, 30+/ 120-$, and $30+/ 240-$ conditions, respectively, of Experiment $1 \mathrm{~b}$. 
ment, followed by a sharp decline and then a slow rise toward the end of the trial. Doubling the PI now eliminated the second peak in much the same way that halving the FI had done earlier. Even though there was an additional 120 $s$ of time on PI trials, the greater opportunity to respond after the FI had elapsed did not produce additional peaks in responding.

Table 2 presents a BRB analysis of the individual trials during the last 6-session block of training for the three phases of Experiment $1 \mathbf{b}$ and the immediately prior phase of $30+1120-$ training in Experiment la. Three major trends can be gleaned from Table 2 . First, when the birds received a 1:8 FI:PI duration ratio $(15+/ 120-$ and $30+1240-$ phases), they produced a higher percentage of BRB trials $(15+1$ $120-.20 .9 \% ; 30+1240-, 29.6 \%)$ than when they received a 1:4 FI:PI duration ratio $(30+/ 120-, 2.7 \%$ overall $)$. The BRB pattern should be observable on a good percentage of the trials if there is only one peak in the average response distribution, as was the case during the $15+/ 120-$ and $30+1240-$ phases (see Figure 3, right column). Second, the incidence of BRBRB trials was higher in both $30+/ 120-$ phases $(34.6 \%$ overall) than in the $15+/ 120-(21.7 \%)$ and $30+1240-(19.6 \%)$ phases. Third, the second presentation of the $30+/ 120-$ procedure (that followed training with a $15+/ 120$ - schedule) resulted in a lower percentage of BRBRB trials $(26.2 \%)$ than was observed in the original $30+/ 120-$ presentation $(42.9 \%)^{\prime}$

\section{Experiment 2}

Because development of the second peak was such an unexpected finding, we undertook further testing to reveal the conditions under which this second peak would occur. We considered two possible conditions for producing a second peak. First, the particular FI and PI combination (30 and $120 \mathrm{~s}$ ) may have contributed to the formation of the second peak. Second, the 1:4 FI:PI duration ratio may have produced the double-peaked response pattern. In Experiment 2 we examined whether double peaks would be produced with combinations of FIs and PIs that comprised different values but were in the same $1: 4$ ratio as in the $30+/ 120-$ condition.

Specifically, we trained three groups of pigeons with 1:4 FI:PI duration ratios made up of different pairs of FI and PI durations. One. Group 30+/120-, was included in an attempt to replicate the double peaks that we had seen in Experiments $1 \mathrm{a}$ and $1 \mathrm{~b}$. The other two, Group $15+160-$ and Group $60+/ 240-$, were included in order to determine the generality of the FI/PI values under which double peaks might be obtained. We gave all three groups of pigeons their respective reinforcement schedules from the inception of experimental training, without any prior FI experience, in an effort to hasten the process of temporal control and to determine whether that prior reinforcement history was necessary for the development of double peaks.

\section{Method}

\section{Subjects}

The subjects were 12 feral pigeons naive to the peak procedure; the birds had participated in previous experiments on visual perception. Their housing conditions were the same as in Experiments $1 \mathrm{a}$ and $1 \mathrm{~b}$.

\section{Apparatus}

The daily sessions were conducted in the same four operant chambers used in Experiments la and $1 \mathrm{~b}$.

\section{Procedure}

The three groups of pigeons were given training with FI and PI durations that were in a $1: 4$ ratio. The $\mathrm{FI}$ and $\mathrm{PI}$ trials were signaled by the red keylight. At the end of the FI duration, food was primed and the first response delivered it. The PI trials always ended in nonreinforcement; the pigeons were not required to peck to end the PI trial. Both FI and PI trials ended with the houselight extinguishing for a duration equal to the hopper activation interval on reinforced FI trials. The houselight was then turned back on during the 5-s fixed ITI and the following trial. Three different FI values were used: $15 \mathrm{~s}, 30 \mathrm{~s}$, and $60 \mathrm{~s}$. The corresponding PI values were $60 \mathrm{~s}, 120 \mathrm{~s}$, and $240 \mathrm{~s}$, yielding the three conditions: $15+/ 60-$. $30+/ 120-$, and $60+/ 240-$. All other aspects of the procedure were the same as in $30+/ 120$ - testing in Experiments $1 \mathrm{a}$ and $1 \mathrm{~b}$ Experiment 2 lasted for 36 days.

\section{Results and Discussion}

Figure 4 shows a superposition plot of the mean rates of response of all three groups of pigeons on Days $31-36$ of training as a function of the percentage of the PI that had elapsed. In all three groups, an initial peak was evident at or near the time of reinforcement on FI trials ( $25 \%$ of the total trial length); as well, a second peak was evident at or near three times the point of reinforcement on FI trials $(75 \%$ of the total trial length). The spread, or width of the peak, was similar for the first and second peaks. Both peaks were slightly more accentuated in Group $15+/ 60-$ than in Groups $30+/ 120-$ and $60+/ 240-$. Thus, the second peak developed when FIs of $15 \mathrm{~s}, 30 \mathrm{~s}$, and $60 \mathrm{~s}$ were scheduled and the FI:PI duration ratio was $1: 4(15+/ 60-, 30+/ 120-$, and $60+/ 240-$ ) even though the FI/PI intermixture was begun at the inception of training and the FI/PI schedule was not FI 30/PI 120.

A BRB analysis was conducted on the final six-session block of FI/PI exposure for the three groups (see Table 3). ${ }^{2}$ The degree of consistency among the groups was substan-

\footnotetext{
I Statistical analyses of the break-run-break data from this and subsequent experiments are reported in the Comparison of Experiments $1-4$ section.

${ }^{2}$ Because the break-run-break analysis was conducted on very different PI durations across the three groups, different-sized bins were used in order to equate the total number of bins per trial across groups. The bin sizes were as follows: 1 s for Group $15+/ 60-, 2$ s for Group $30+/ 120-$, and $4 \mathrm{~s}$ for Group $60+/ 240-$
} 
Table 2

Results of a Break-Run-Break Analysis for the

$30+1120-$ Condition in Experiment la and the

$15+/ 120-, 30+/ 120-$, and $30+/ 240-$ Phases

During the Final Block of Peak Interval Exposure in Experiment $1 \mathrm{~b}$

\begin{tabular}{lrrrrr}
\hline Phase and pattern & Bird 5 & Bird 6 & Bird 7 & Bird 8 & $M$ \\
\hline \multicolumn{5}{c}{ Experiment 1a } \\
Phase 30+/120- & & & & & \\
BR & 1.7 & 0.0 & 11.7 & 0.0 & 3.3 \\
BRB & 6.7 & 3.3 & 0.0 & 0.0 & 2.5 \\
BRBR & 38.3 & 33.3 & 36.7 & 25.0 & 33.3 \\
BRBRB & 51.7 & 38.3 & 31.7 & 50.0 & 42.9 \\
BRBRBR & 1.7 & 18.3 & 11.7 & 20.0 & 12.9 \\
BRBRBRB & 0.0 & 3.3 & 3.3 & 3.3 & 2.5 \\
Other & 0.0 & 3.3 & 5.0 & 1.7 & 2.5 \\
& & & & &
\end{tabular}

\begin{tabular}{lrrrrr} 
Phase 15+/120- & & & & & \\
BR & 0.0 & 0.0 & 3.3 & 0.0 & 0.8 \\
BRB & 26.7 & 16.7 & 3.3 & 36.7 & 20.9 \\
BRBR & 31.7 & 26.7 & 35.0 & 20.0 & 28.4 \\
BRBRB & 20.0 & 30.0 & 10.0 & 26.7 & 21.7 \\
BRBRBR & 10.0 & 16.7 & 38.3 & 11.7 & 19.2 \\
BRBRBRB & 8.4 & 5.0 & 3.3 & 5.0 & 5.4 \\
Other & 3.3 & 5.0 & 6.7 & 0.0 & 3.8 \\
Phase 30+/120- & & & & & \\
BR & 6.7 & 20.0 & 10.0 & 5.0 & 10.4 \\
BRB & 3.3 & 1.7 & 5.0 & 1.7 & 2.9 \\
BRBR & 51.7 & 28.3 & 33.3 & 46.7 & 40.0 \\
BRBRB & 28.3 & 18.3 & 23.3 & 35.0 & 26.2 \\
BRBRBR & 10.0 & 29.3 & 20.0 & 11.7 & 17.5 \\
BRBRBRB & 0.0 & 3.3 & 3.3 & 0.0 & 1.7 \\
Other & 0.0 & 0.0 & 5.0 & 0.0 & 1.3 \\
Phase 30+/240- & & & & & \\
BR & 11.7 & 0.0 & 21.7 & 1.7 & 8.8 \\
BRB & 31.7 & 45.0 & 3.3 & 38.3 & 29.6 \\
BRBR & 16.7 & 5.0 & 50.0 & 48.3 & 30.0 \\
BRBRB & 26.7 & 31.7 & 11.7 & 8.3 & 19.6 \\
BRBRBR & 3.3 & 3.3 & 13.3 & 3.3 & 5.8 \\
BRBRBRB & 6.7 & 11.7 & 0.0 & 0.0 & 4.6 \\
Other & 3.3 & 3.3 & 0.0 & 0.0 & 1.7 \\
\hline
\end{tabular}

Note. The data are expressed as the percentage of total trials conforming to a given pattern. $\mathrm{BR}=$ break-run, $\mathrm{BRB}=$ breakrun-break, etc.; Other $=$ those trials that failed to conform to any of the listed patterns.

tial. The overall modal response pattern for all three groups was BRBRB $(15+/ 60-, 41.3 \% ; 30+/ 120-, 35.0 \% ; 60+/$ $240-, 44.6 \%$ ). A BRBR pattern was also fairly prevalent in all three groups $(15+/ 60-, 35.4 \% ; 30+/ 120-, 34.6 \%$; $60+/ 240-, 27.1 \%)$. Finally, the third most common pattern was BRBRBR $(15+/ 60-, 13.3 \% ; 30+/ 120-, 20.8 \% ; 60+/$ $240-, 15.4 \%)$. These three response patterns all involved at least two runs of responding and they constituted $90.0 \%$, $90.4 \%$, and $87.1 \%$ of the total trials for the $15+/ 60-$, $30+/ 120-$, and $60+/ 240-$ groups, respectively.

As a result, each bird's patterns of breaking and running are based on 60 bins per trial. The criterion for identifying breaks and runs ( 3 consecutive bins with responses $=$ start of a run; 3 consecutive bins without responses $=$ start of a break) was then implemented for each trial on the 60 bins of responding.
The 1:4 FI:PI duration ratio appears to be highly effective in producing double peaks on the FI/PI procedure. FIs of 15 $\mathrm{s}$ and $30 \mathrm{~s}$, when paired respectively with PIs of $120 \mathrm{~s}$ and $240 \mathrm{~s}$ to create a 1:8 FI:PI duration ratio in the $15+/ 120-$ and $30+/ 240-$ schedules, did not support double peaks in Experiment 1b. In Experiment 2, however, when different PI values were used in conjunction with the same FI durations of $15 \mathrm{~s}$ and $30 \mathrm{~s}$ to create a 1:4 FI:PI duration ratio in the $15+/ 60-$ and $30+/ 120-$ schedules, double peaks did emerge.

\section{Experiment 3}

Experiment $\mathrm{lb}$ disclosed an important role of the 1:4 FI:PI duration ratio in producing the double-peaked response distribution. Double peaks appeared when the birds were exposed to a 1:4 ratio, but not when they were exposed to a $1: 8$ ratio. By using different combinations of $\mathrm{FI}$ and $\mathrm{PI}$ values, in Experiment 2 we showed that a 1:4 ratio will produce double peaks despite variations in the durations of the FI and PI intervals.

It is possible that the double peaks in our experiments were the result of a natural internal oscillator that was initiated by some aspect of our procedure. In our attempts to isolate this factor so far, we had explored the FI:PI ratio. However, there was another factor-beyond the 1:4 FI:PI ratio-that remained the same in all of the conditions that produced double peaks: The FI and PI values were all 15-s harmonics $(15+/ 60-, 30+/ 120-$, and $60+/ 240-)$, with the response peaks also occurring at intervals containing a 15 -s harmonic (15 and $45 \mathrm{~s}, 30$ and $90 \mathrm{~s}$, and 60 and $180 \mathrm{~s}$; see Figure 4). With this consideration in mind, it is possible that (a) a 1:4 ratio alone produces two peaks or (b) something about the combination of a 1:4 ratio and a 15-s harmonic produces two peaks. We designed Experiment 3 to examine this issue.

In order to test the possibility that a 15-s harmonic influenced the development of double peaks, we eliminated 15-s harmonic values but retained the 1:4 FI:PI duration ratio. If a 15-s harmonic is necessary for producing the doublepeaked response pattern, then we should not see double peaks under conditions in which the FI and PI durations are not evenly divisible by $15 \mathrm{~s}$. Thus, we chose an FI of $38 \mathrm{~s}$,

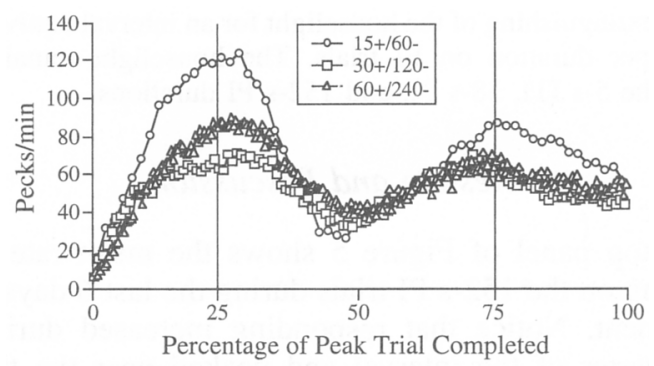

Figure 4. A superposition plot that displays response rate as a function of the percentage of the peak interval trial in the final 6-day block for Groups $15+/ 60-, 30+/ 120-$, and $60+/ 240-$ in Experiment 2. 
Table 3

Break-Run-Break Results for Groups 15+/60-, 30+/120-, and 60+/240-During the Final Block of Peak Interval Exposure in Experiment 2

\begin{tabular}{|c|c|c|c|c|c|c|c|c|c|c|c|c|c|c|c|}
\hline \multirow[b]{2}{*}{ Pattern } & \multicolumn{5}{|c|}{ Group $15+160-$} & \multicolumn{5}{|c|}{ Group $30+/ 120-$} & \multicolumn{5}{|c|}{ Group $60+/ 240-$} \\
\hline & Bird 1 & Bird 2 & Bird 3 & Bird 4 & $M$ & Bird 5 & Bird 6 & Bird 7 & Bird 8 & $M$ & Bird 9 & Bird 10 & Bird 11 & Bird 12 & $M$ \\
\hline $\mathrm{BR}$ & 0.0 & 0.0 & 1.7 & 0.0 & 0.4 & 1.7 & 0.0 & 15.0 & 0.0 & 4.2 & 5.0 & 1.7 & 0.0 & 6.7 & 3.4 \\
\hline BRB & 3.3 & 6.7 & 1.7 & 1.7 & 3.4 & 0.0 & 1.7 & 3.3 & 0.0 & 1.3 & 6.7 & 5.0 & 0.0 & 5.0 & 4.2 \\
\hline BRBR & 50.0 & 15.0 & 30.0 & 46.7 & 35.4 & 40.0 & 28.3 & 40.0 & 30.0 & 34.6 & 16.7 & 33.3 & 31.7 & 26.7 & 27.1 \\
\hline BRBRB & 45.0 & 51.7 & 43.3 & 25.0 & 41.3 & 43.3 & 43.3 & 26.7 & 26.7 & 35.0 & 41.7 & 41.7 & 45.0 & 50.0 & 44.6 \\
\hline BRBRBR & 1.7 & 18.3 & 18.3 & 15.0 & 13.3 & 11.7 & 23.3 & 13.3 & 35.0 & 20.8 & 25.0 & 13.3 & 15.0 & 8.3 & 15.4 \\
\hline BRBRBRB & 0.0 & 8.3 & 1.7 & 5.0 & 3.8 & 3.3 & 3.3 & 1.7 & 6.7 & 3.8 & 5.0 & 5.0 & 8.3 & 3.3 & 5.4 \\
\hline Other & 0.0 & 0.0 & 3.3 & 6.7 & 2.5 & 0.0 & 0.0 & 0.0 & 1.7 & 0.4 & 0.0 & 0.0 & 0.0 & 0.0 & 0.0 \\
\hline
\end{tabular}

Note. The results are expressed as a percentage of the total trials conforming to a given pattern. $\mathrm{BR}=\mathrm{break}-\mathrm{run}, \mathrm{BRB}=$ break-run-break, etc.; Other $=$ those trials that failed to conform to any of the listed patterns.

a value about halfway between $30 \mathrm{~s}$ and $45 \mathrm{~s} .{ }^{3}$ The PI was $152 \mathrm{~s}$, a value that is four times $38 \mathrm{~s}$. If a 1:4 ratio alone is responsible for producing two response peaks, then regardless of the specific values that are used to satisfy the ratio, we should still see double peaks under the $38+/ 152-$ schedule.

\section{Method}

\section{Subjects}

Four new feral pigeons served as subjects. They were naive to the peak procedure, but they had participated in prior studies on visual perception. The birds were housed as in prior experiments.

\section{Apparatus}

The experiment was conducted in the same four operant boxes used in earlier projects.

\section{Procedure}

In the 36 daily sessions of Experiment 3 , the birds were given 40 FI $38-\mathrm{s}$ and 10 PI 152-s trials. A session began with 10 FI trials alone; then, a mixture of FI and PI trials followed in four-trial blocks that consisted of three FI trials and one PI trial. The FI trials always ended in response-dependent reinforcement, whereas the PI trials always ended in response-independent nonreinforcement. Both intervals were timed by the red keylight, and the end of all trials was dually signaled by (a) extinguishing of the red keylight and (b) extinguishing of the houselight for an interval equivalent to the hopper duration on FI trials. The houselight remained on during the 5-s ITI, 38-s FI, and 152-s PI durations.

\section{Results and Discussion}

The top panel of Figure 5 shows the mean rate of responding on the 152-s PI trials during the last 6 days of the experiment. Notice that responding increased during the first quarter of the interval and peaked near the time of reinforcement on the FI trials. After the first peak, responding fell until the middle of the trial and then rose, resulting in a second peak near the third quarter of the PI; responding then declined toward the end of the PI.
Table 4 displays the BRB analysis on individual trials for Days 31-36. Notice that the dominant overall response pattern was BRBRB, which accounted for $40.0 \%$ of the trials, whereas only $15.4 \%$ of the trials were characterized by a single run (BR and $B R B$ patterns combined).

The important conclusion to draw from Experiment 3 is that, because the FI and PI durations were not evenly divisible by $15 \mathrm{~s}$, the double-peaked response pattern does not require a 15 -s harmonic. Therefore, we can be more confident that a 1:4 FI:PI duration ratio will produce double peaks across a variety of specific time values that are used to satisfy the ratio.

\section{Experiment 4}

The $15+/ 120-$ and $30+/ 240-$ training phases of Experiment $1 \mathrm{~b}$ disclosed that shifting from a $1: 4$ to a 1:8 FI:PI duration ratio disrupted the double-peaked response pattern. We had initially expected to see four peaks in the 1:8 conditions; however, the disappearance of the double peaks after 1:4 training led us to consider the possibility that the double-peaked response pattern may be observed only when the FI and PI values are in a 1:4 ratio. Another possibility is that double peaks were not found in the 1:8 condition because of interference from earlier 1:4 training. We thought it would be interesting to see whether multiple peaks would develop with initial 1:8 training. We designed Experiment 4 to explore this issue.

Four new pigeons were exposed to a $38+/ 304-$ procedure (1:8 ratio) for 36 days. They were then given an additional 36 sessions with a $38+/ 152-$ procedure (1:4 ratio). Double peaks were found only in the $38+1152-$ phase and did not appear to be prevented by the initial $1: 8$ FI:PI duration ratio training.

\footnotetext{
${ }^{3}$ The value of 38 was chosen against the alternative and precise midpoint of 37.5 because of the necessity of 2 -s bins for the data analysis.
} 

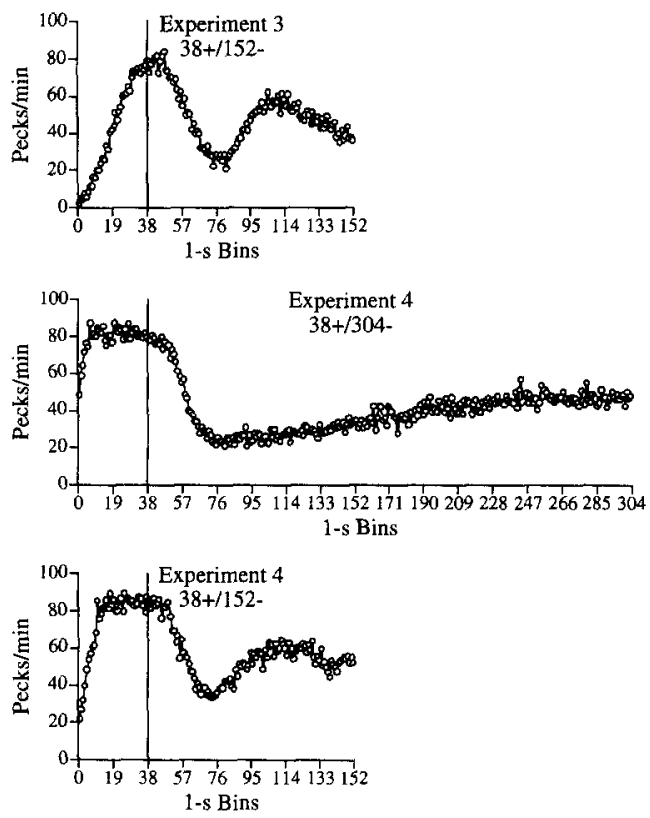

Figure 5. Response rate in successive 1-s bins for the final 6-day block. The top panel shows the results of $38+/ 152$ - training in Experiment 3 . The middle and bottom panels display the results of the $38+/ 304-$ and $38+/ 152-$ training phases, respectively, in Experiment 4.

\section{Method}

\section{Subjects}

Four new feral pigeons served as subjects. They were naive to the peak procedure, but they had participated in previous experiments on visual perception. The pigeons were housed as described in earlier experiments.

\section{Apparatus}

The experiment was conducted in the same four operant chambers used in prior experiments.

\section{Procedure}

$38+/ 304-$ training. During $38+/ 304-$ training, the birds were given 40 FI 38-s trials that ended in reinforcement and $10 \mathrm{PI}$ 304-s trials that ended in nonreinforcement. After the first $10 \mathrm{FI}$ 38-s trials, 10 nonreinforced PI 304-s trials were intermixed with the remaining 30 FI 38 -s trials in 10 four-trial blocks. Each block contained three FI 38-s trials and one PI 304-s trial, randomly distributed. On FI trials, the first peck after $38 \mathrm{~s}$ produced grain and extinguished the red keylight and houselight; the houselight was extinguished for a period equal to the hopper duration on FI trials (range $=0.75$ to $5.00 \mathrm{~s}$ ). On PI trials, the red keylight and houselight were extinguished at the end of the 304-s PI regardless of responding. The houselight remained on during the ITI, FI, and PI durations. All trials were separated by a 5-s ITI. Training lasted for 36 days.

$38+/ 152-$ training. During $38+/ 152-$ training, the PI trials were shifted to $152 \mathrm{~s}$ while the FI remained at $38 \mathrm{~s}$. All other aspects of the procedure were the same as in the earlier $38+/ 304-$ training phase. Training lasted for 36 days.

\section{Results and Discussion}

\section{$38+/ 304-$ Training}

The middle panel of Figure 5 displays the mean rate of responding on the PI 304-s trials during the last 6 days of training. Notice that the high rate of responding up to the time of reinforcement on the FI trials was followed by a rapid decline to $76 \mathrm{~s}$, followed by a gradual rise toward the end of the PI at $304 \mathrm{~s}$. Here, there do not appear to be any signs of a cyclical pattern in responding. This fact plus the disappearance of double peaks in Experiment 1b, when the birds were exposed to a 1:8 ratio (on the $15+/ 120-$ and $30+/ 240$ - schedules), suggests that a 1:8 FI:PI duration ratio by itself will not produce or sustain a cyclical response pattern.

The BRB analysis shown in Table 5 revealed that $43.7 \%$ of the individual trials during the last 6 days of training were characterized by a single run (BR and BRB patterns combined). Only $13.8 \%$ of the trials involved the BRBRB pattern. The fact that $27.1 \%$ of the trials involved a BRBR pattern is not surprising given the rise in response rate toward the end of the trial (see Figure 5, middle panel); this second run was not a second peak, but rather a gradual increase in responding, not uncharacteristic of long PI trials (cf. Church et al., 1991).

Additional peaks in responding beyond $38 \mathrm{~s}$ did not appear to develop under initial training with a 1:8 FI:PI duration ratio. So it appears that the failure of the $1: 8$ training ratio to support multiple peaks in Experiment $1 \mathrm{~b}$ was not due to the birds' prior experience with the 1:4 ratio. The fact that a 1:8 training ratio does not produce double peaks increases our confidence that the FI:PI duration ratio is a key factor in determining whether the double-peaked response distribution will arise.

\section{$38+/ 152-$ Training}

The bottom panel of Figure 5 shows the mean rate of responding on the PI 152-s trials during the last 6 days of

Table 4

Results of a Break-Run-Break Analysis of the 152-s Peak Trials From Days 31-36 of Experiment 3

\begin{tabular}{lrrrrr}
\hline \multicolumn{1}{c}{ Pattern } & Bird 1 & Bird 2 & Bird 3 & Bird 4 & \multicolumn{1}{c}{$M$} \\
\hline BR & 11.7 & 13.3 & 3.3 & 3.3 & 7.9 \\
BRB & 10.0 & 8.3 & 6.7 & 5.0 & 7.5 \\
BRBR & 35.0 & 35.0 & 18.3 & 20.0 & 27.1 \\
BRBRB & 38.3 & 36.7 & 45.0 & 40.0 & 40.0 \\
BRBRBR & 1.7 & 1.7 & 23.3 & 15.0 & 10.4 \\
BRBRBRB & 3.3 & 5.0 & 3.3 & 16.7 & 7.1 \\
Other & 0.0 & 0.0 & 0.0 & 0.0 & 0.0 \\
\hline
\end{tabular}

Note. The data are expressed as the percentage of total trials conforming to a given pattern for both individual birds and for the mean of the 4 birds. BR = break-run, BRB = break-run-break, etc.; Other $=$ those trials that failed to conform to any of the listed patterns. 
Table 5

Results of a Break-Run-Break Analysis of the First $152 \mathrm{~s}$ of the 304-s Peak Trials From Days 31-36 of the 38+/ 304- Training Phase in Experiment 4

\begin{tabular}{lrrrrr}
\hline \multicolumn{1}{c}{ Pattern } & Bird 1 & Bird 2 & Bird 3 & Bird 4 & \multicolumn{1}{c}{$\boldsymbol{M}$} \\
\hline BR & 13.3 & 0.0 & 21.7 & 8.3 & 10.8 \\
BRB & 30.0 & 80.0 & 11.7 & 10.0 & 32.9 \\
BRBR & 30.0 & 10.0 & 50.0 & 18.3 & 27.1 \\
BRBRB & 6.7 & 5.0 & 8.3 & 35.0 & 13.8 \\
BRBRBR & 16.7 & 3.3 & 8.3 & 16.7 & 11.3 \\
BRBRBRB & 1.7 & 0.0 & 0.0 & 8.3 & 2.5 \\
Other & 1.7 & 1.7 & 0.0 & 3.3 & 1.7 \\
\hline
\end{tabular}

Note. The data are expressed as the percentage of total trials conforming to a given pattern for both individual birds and for the mean of the 4 birds. BR $=$ break-run, BRB $=$ break-run-break, etc.; Other $=$ those trials that failed to conform to any of the listed patterns.

training. As in Experiment 3, the first peak is near $38 \mathrm{~s}$ and the second peak is near $114 \mathrm{~s}$, with a nadir occurring close to the middle of the trial. Again, we see a double-peaked response pattern characteristic of the 1:4 FI:PI duration ratio, although the final fall toward the end of the trial is not as pronounced as in earlier experiments.

Table 6 displays the BRB analysis for the individual PI 152-s trials on Days 31-36. The three most prevalent response patterns were BRBR, BRBRB, and BRBRBR, all of which contain two runs of responding. The overall percentage of responses falling in the BRBR, BRBRB, and BRBRBR categories was $32.1 \%, 26.7 \%$, and $18.3 \%$, respectively, scores that total $77.1 \%$ of all patterns and that are consistent with the double peaks shown in Figure 5 (bottom panel).

In summary, the double peaks observed here (bottom panel of Figure 5) were similar to the double peaks observed in Experiment 3, where the birds had no prior experience with a $1: 8$ ratio (top panel of Figure 5). However, the BRB data revealed that the birds in Experiment 3 that were first exposed to the $1: 4$ ratio produced an average of $13.3 \%$ more BRBRB patterns (the perfect pattern for a double-peaked response distribution) than the birds in Experiment 4, which were first exposed to a 1:8 ratio and then shifted to a $1: 4$ ratio. Therefore, initial exposure to a $1: 8$ ratio may to some degree weaken, but not prevent, the subsequent acquisition of a double-peaked response pattern.

\section{Comparison of Experiments 1-4}

The results of Experiments 1-4 suggest that the 1:4 FI:PI ratio was responsible for producing double peaks on PI trials. When the FI:PI ratio was $1: 8$, only a single peak was generally observed.

In order to better index the effects of the various FI/PI conditions on the production of double peaks, we grouped together those temporal response patterns that would be consistent with the presence of two peaks in the response distribution. The purest instance of double peaks would of course be evidenced by a BRBRB pattern. But it is con- ceivable that with such an elaborate temporal pattern the pigeons may occasionally "mistime" some intervals; responding could begin a tad too early and result in an extra partial cycle (BRBRBR), or responding could begin a tad too late and result in a partially truncated final cycle (BRBR). In both the BRBR and BRBRBR patterns, at least two response runs would have been produced; thus, these patterns could represent a tendency to produce two peaks that would be slightly out of phase from the perfect BRBRB pattern.

The percentages of patterns falling within the combined categories of BRBR, BRBRB, and BRBRBR are presented in Table 7 for each of the different conditions in Experiments $1 \mathrm{a}, 1 \mathrm{~b}, 2,3$, and 4 . The fourth column indicates the number of peaks in the mean response distributions depicted in Figures 2-5. Those conditions that produced two peaks in the mean response distributions in Figures 2-5 also evidenced a high percentage of response patterns of the above three types, whereas those conditions that failed to produce two peaks evidenced a much lower percentage of these three response patterns. The overall percentage of trials conforming to the three combined response patterns was $85.0 \%$ when double peaks were produced; in contrast, the overall percentage of trials conforming to the three combined response patterns was only $59.0 \%$ when double peaks were not produced.

In order to statistically evaluate the differences in the response patterns when double peaks were or were not produced, we counted the number of individual scores that exceeded $70 \%$ across all of the conditions (these scores are shown in boldface in Table 7). For the seven different conditions in which double peaks were observed, 27 of the 28 cases had more than $70 \%$ of the individual trials fall into the three response categories; on the other hand, for the three conditions that failed to support double peaks, only 3 of the 12 cases had more than $70 \%$ of the individual trials fall into the three response categories. A chi-square analysis of the number of cases that did and did not exceed the $70 \%$ criterion verified the above descriptive remarks, $\chi^{2}(1, n=$ $40)=22.86, p<.001$. Critically, all of the conditions that

Table 6

Results of a Break-Run-Break Analysis of the 152-s Peak Trials From Days 31-36 of the 38+1152- Training Phase in Experiment 4

\begin{tabular}{lrrrrr}
\hline \multicolumn{1}{c}{ Pattern } & Bird 1 & Bird 2 & Bird 3 & Bird 4 & \multicolumn{1}{c}{$M$} \\
\hline BR & 1.7 & 5.0 & 13.3 & 6.7 & 6.7 \\
BRB & 1.7 & 15.0 & 1.7 & 5.0 & 5.9 \\
BRBR & 33.3 & 23.3 & 51.7 & 20.0 & 32.1 \\
BRBRB & 36.7 & 20.0 & 6.7 & 43.3 & 26.7 \\
BRBRBR & 21.7 & 18.3 & 23.3 & 10.0 & 18.3 \\
BRBRBRB & 3.3 & 11.7 & 1.7 & 13.3 & 7.5 \\
Other & 1.7 & 6.7 & 1.7 & 1.7 & 3.0 \\
\hline
\end{tabular}

Note. The data are expressed as the percentage of total trials conforming to a given pattern for both individual birds and for the mean of the 4 birds. BR $=$ break-run, BRB $=$ break-run-break, etc.; Other $=$ those trials that failed to conform to any of the listed patterns. 
Table 7

Combined Percentages of Individual Trials That Fell in the BRBR, BRBRB, and BRBRBR Categories in Experiments $1 a, 1 b, 2,3$, and 4

\begin{tabular}{ccccccccc}
\hline Experiment & Condition & FI:PI ratio & Peaks & Bird A & Bird B & Bird C & Bird D & $M$ \\
\hline la & $30+/ 120-$ & $1: 4$ & 2 & $\mathbf{9 1 . 7}$ & $\mathbf{8 9 . 9}$ & $\mathbf{8 0 . 1}$ & $\mathbf{9 5 . 0}$ & $\mathbf{8 9 . 1}$ \\
lb & $15+/ 120-$ & $1: 8$ & 1 & 61.7 & $\mathbf{7 3 . 4}$ & $\mathbf{8 3 . 3}$ & 58.4 & 69.3 \\
lb & $30+/ 120-$ & $1: 4$ & 2 & $\mathbf{9 0 . 0}$ & $\mathbf{7 5 . 9}$ & $\mathbf{7 6 . 6}$ & $\mathbf{9 3 . 4}$ & $\mathbf{8 3 . 7}$ \\
1b & $30+/ 240-$ & $1: 8$ & 1 & 46.7 & 40.0 & $\mathbf{7 5 . 0}$ & 59.9 & 55.4 \\
2 & $15+/ 60-$ & $1: 4$ & 2 & $\mathbf{9 6 . 7}$ & $\mathbf{8 5 . 0}$ & $\mathbf{9 1 . 6}$ & $\mathbf{8 6 . 7}$ & $\mathbf{9 0 . 0}$ \\
2 & $30+/ 120-$ & $1: 4$ & 2 & $\mathbf{9 5 . 0}$ & $\mathbf{9 4 . 9}$ & $\mathbf{8 0 . 0}$ & $\mathbf{9 1 . 7}$ & $\mathbf{9 0 . 4}$ \\
2 & $60+/ 240-$ & $1: 4$ & 2 & $\mathbf{8 3 . 4}$ & $\mathbf{8 8 . 8}$ & $\mathbf{9 1 . 7}$ & $\mathbf{8 5 . 0}$ & $\mathbf{8 7 . 1}$ \\
3 & $38+/ 152-$ & $1: 4$ & 2 & $\mathbf{7 5 . 0}$ & $\mathbf{7 3 . 4}$ & $\mathbf{8 6 . 6}$ & $\mathbf{7 5 . 0}$ & $\mathbf{7 7 . 5}$ \\
4 & $38+/ 304-$ & $1: 8$ & 1 & 53.4 & 18.3 & 66.6 & 70.0 & 52.2 \\
4 & $38+/ 152-$ & $1: 4$ & 2 & $\mathbf{9 1 . 7}$ & 61.6 & $\mathbf{8 1 . 7}$ & $\mathbf{7 3 . 3}$ & $\mathbf{7 7 . 1}$ \\
\hline
\end{tabular}

Note. The percentages are presented for the individual birds as well as for the group average. The data for the reinforcement condition in Experiment 1a were not included. The percentages that exceeded $70 \%$ are indicated in bold. Birds A, B, C, and D refer to the first, second, third, and fourth birds, respectively, in each condition. For the specific bird numbers, consult the individual experiments. $\mathrm{B}=$ break; $\mathrm{R}=$ run; $\mathbf{F I}=$ fixed interval; $\mathrm{PI}=$ peak interval.

supported double peaks (and that exceeded the $70 \%$ criterion) involved the 1:4 FI:PI ratio; all of the conditions that did not support double peaks (and that did not exceed the $70 \%$ criterion) involved the 1:8 FI:PI ratio (see the second, third, and fourth columns of Table 7).

\section{Experiment 5}

Having found that double peaks were obtainable with a 1:4 FI:PI duration ratio, we were interested in whether or not responding could continue to cycle beyond the end of the PI. We suspected that simply lengthening the PI would not work because of the loss in double peaks that resulted when going from $30+/ 120$ - to $30+/ 240$ - in Experiment $1 \mathrm{~b}$. So, we randomly intermixed 10 additional 304-s PI trials with the original $38+/ 152-$ design used in Experiment 3 . This 1:4:8 FI:PI:PI intermixture might prove effective in allowing us to see more than two cycles in an expanded PI procedure.

\section{Method}

\section{Subjects}

The subjects in Experiment 5 were the same as those in Experiment 3.

\section{Apparatus}

The experiment was conducted in the same four operant chambers used in prior experiments.

\section{Procedure}

The experimental sessions began on the day following Day 36 of Experiment 3, in which the pigeons were trained with FI 38-s and PI 152-s trials. During Experiment 5, the birds were presented with 40 FI 38-s trials that ended in reinforcement, 10 PI 152-s trials that ended in nonreinforcement, and 10 PI 304-s trials that also ended in nonreinforcement. After the first 10 trials of the FI 38-s schedule, 10 nonreinforced PI 152-s trials and 10 nonreinforced PI 304 -s trials were intermixed with the remaining 30 FI 38 -s trials in 10 five-trial blocks; each five-trial block contained three FI 38-s trials, one PI 152-s trial, and one PI 304-s trial, randomly distributed. The red keylight was lit for the duration of all three intervals. On FI trials, the first peck after $38 \mathrm{~s}$ produced access to the grain hopper, whereas on both 152-s and 304-s PI trials, the interval ended whether or not a response occurred. The end of all three intervals was signaled by extinguishing the houselight for a period equal to the hopper duration on FI trials. Experiment 5 lasted for 42 days.

\section{Results and Discussion}

Continued cycling throughout the 304-s peak trials was exhibited by all 4 birds during different blocks of sessions over the course of training. Figure 6 displays the mean response rates for the 6-day blocks in which continued cycling appeared to be most prominent (middle panels). For each of the 4 birds, the blocks immediately preceding and following that block are shown as well (top and bottom panels). In each graph where continued cycling is clearest, the first and second peaks are similar to those observed for the same pigeons in Experiment 3 (see top panel of Figure 5 ), with the first and highest peak at or near the FI value of $38 \mathrm{~s}$ and the second lower peak at around $114 \mathrm{~s}(3 \times 38 \mathrm{~s})$. But the most interesting finding of this experiment was that cyclic PI responding continued throughout the 304-s interval, resulting in two additional peaks beyond the two observed earlier with a 152-s interval.

Four full cycles can clearly be seen for both Birds 1 and 2. For these 2 pigeons, cycling appeared to revolve around the FI value of $38 \mathrm{~s}$, with peaks occurring near $38,114,190$, and $266 \mathrm{~s}$, and troughs near 76, 152, 288, and $304 \mathrm{~s}$. For Birds 3 and 4 , the data were not quite as clear, disclosing only $31 / 2$ cycles. Although several peaks were seen for these 2 pigeons, the location of each peak was different. Bird 3 produced peaks around $38,152,228$, and $285 \mathrm{~s}$; Bird 4 produced peaks around $38,114,210$, and $295 \mathrm{~s}$. 

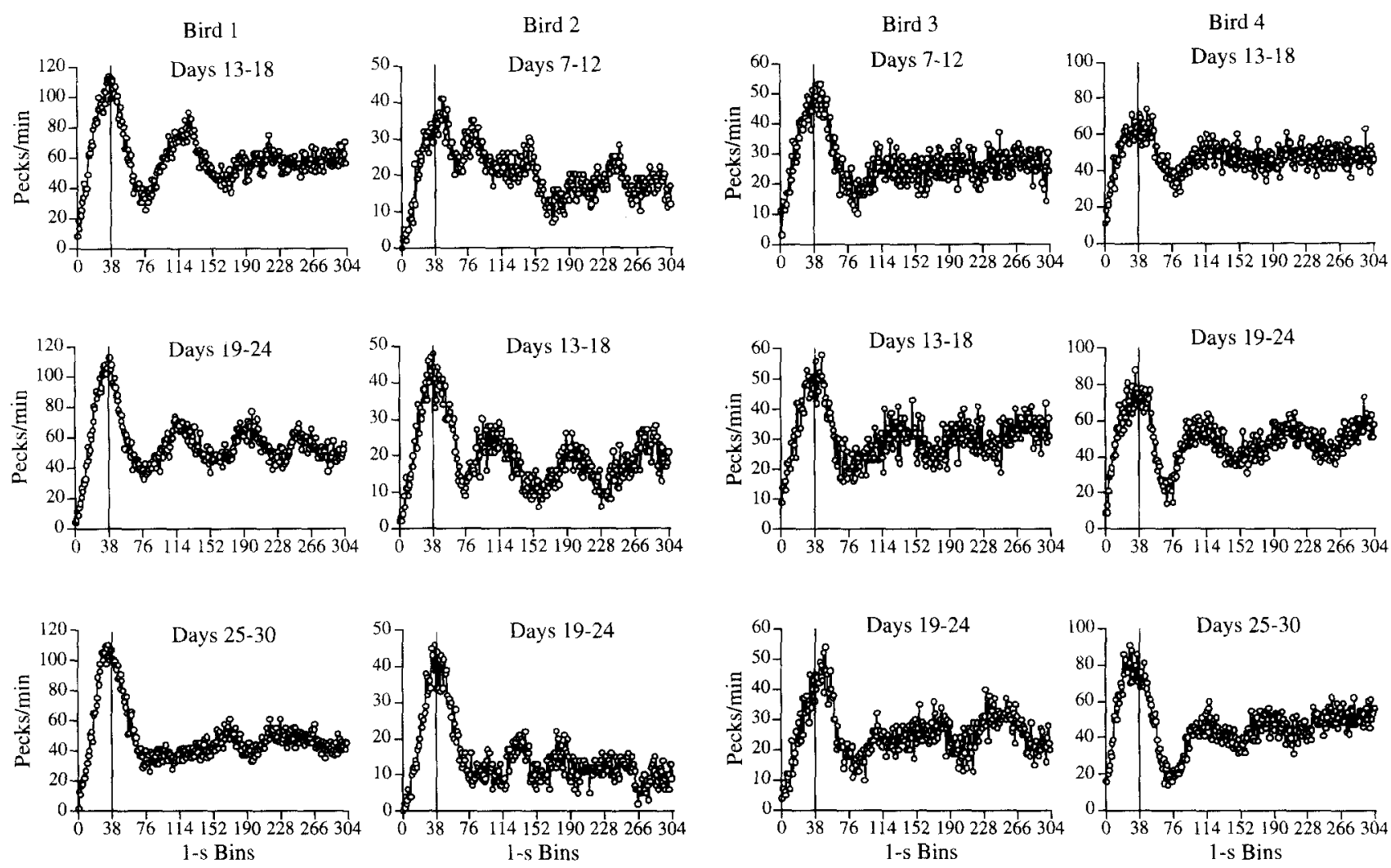

Figure 6. Response rate in successive 1 -s bins from the 304-s peak trials of $38+/ 152-/ 304-$ training. The middle panel displays, for each of the 4 birds in Experiment 5, the 6-day block in which consistent cycling was clearest. The top and bottom panels show the 6-day blocks immediately preceding and following the clearest block.

Given the failure of the 1:8 FI:PI ratio to support multiple peaks in Experiments $1 \mathrm{~b}$ and 4, the inclusion of the $1: 4$ ratio in Experiment 5 appears to be responsible for the cycling response patterns. The $1: 8$ ratio is not sufficient to support cycling; yet, as can be seen here, longer probe trials may be useful in revealing the tendency for the 1:4 ratio to support continued cycling. The transient nature of the multiple peaks in Experiment 5 is perhaps due to the 1:8 ratio's disruptive influence on cycling behavior. It would be interesting in future work to see whether better evidence of cycling could be obtained by including even fewer long peak trials per session.

\section{General Discussion}

Experiment 1a disclosed that the pigeon's distribution of operant responses in time changed as a result of prolonged exposure to FI and PI trials (see Figure 2). Thus, the single symmetrical response peak that is usually seen on nonreinforced PI trials around the time of reinforcement on FI trials is not due simply to FI exposure; rather, the peak appears to require exposure to both FI and PI trials in order to develop. The requirement of both FI and PI trials for the production of a symmetrical peak highlights the role of learning in the peak procedure. Two sources of learning can be hypothe- sized: learning to produce high response rates at the time of food availability on FI trials and learning to withhold responding after that time has passed on PI trials. These two sources of learning cannot be isolated under normal peak procedure conditions-where the FI and PI trials are intermixed from the onset of training - because learning about both types of trials would occur concurrently. However, by first training the FI and then adding the PI, one can isolate the two sources of learning.

Although introducing the PI trials changed the temporal response distributions, the alterations in operant responding occurred predominantly past the time of reinforcement on FI trials; this was true whether the PI trials ended with reinforcement or nonreinforcement. The response distributions in Group 30+/120+ were consistent with a reinforcement interpretation; because reinforcement was available at two times-30 and $120 \mathrm{~s}$-responding should have been high at those times (Catania \& Reynolds, 1968). The surprising result of Experiment 1a was the response distribution produced by the pigeons in the nonreinforcement condition $(30+/ 120-)$; these birds produced two peaks in responding, one at $30 \mathrm{~s}$ and one at $90 \mathrm{~s}$ (see the right column of Figure 2).

To illustrate just how surprising this result is, imagine trying to create these double peaks with standard reinforce- 
ment procedures. The obvious way to do so would be to schedule simultaneously reinforced FIs of 30 and $90 \mathrm{~s}$, each signaled by the same keylight stimulus. The fact is, however, that such multiple FIs involving intervals in less than a 1:4 FI:FI ratio do not generate two peaks in responding, as shown by Leak and Gibbon (1995). Rather, responding rises up to the time of the first FI and thereafter remains high until the time of the second FI. Similarly, in Experiment la, our pigeons in Group $30+/ 120+$ produced high rates of responding near the times of the two reinforced intervals, but responding remained quite high between the first and second peaks, causing both peaks to be rather poorly defined. Thus, something special must have been at work in our procedures that succeeded in generating well-defined double peaks when standard reinforcement procedures failed to do so.

In Experiments $1 \mathrm{~b}-4$ we determined that the second peak (a) was not a function of the specific duration of the FI or the PI (Experiment $1 \mathrm{~b}$ ), (b) did not require prior training with the FI alone (Experiment 2), (c) could be obtained with three different combinations of FI and PI durations provided that the FI:PI duration ratio was 1:4 (Experiment 2), (d) did not require FI and PI durations that were evenly divisible by $15 \mathrm{~s}$ (Experiment 3), and (e) could not be obtained when the FI:PI duration ratio was $1: 8$ (Experiments $1 \mathrm{~b}$ and 4 ). Moreover, four peaks were obtained when the pigeons were trained with the $38+/ 152-/ 304-$ procedure in Experiment 5 (see Figure 6), which demonstrated that the 1:4 ratio created a tendency for the birds to respond in a cyclical fashion. The four peaks were approximately evenly spaced, with a peak occurring at the time of reinforcement $(t)$ and with additional peaks occurring at $3 t, 5 t$, and $7 t$. Incidentally, the peak at $5 t$ occurred at the same time as the interfood interval between the onset of the PI trial and delivery of food on the following FI trial when the pigeons were given the 1:4 FI:PI duration ratio (e.g., 152-s PI + 38-s $\mathrm{FI}+5-\mathrm{s} \mathrm{ITI}=195 \mathrm{~s}$, which is the approximate time of the third peak in Experiment 5).

Periodicities in operant responding have never before been reported with a simple peak procedure in which food is delivered at a single FI, but Broadbent (1994) did report periodic operant behavior when rats were trained with a random interval (RI) schedule (RI 60-s and RI 120-s were used). Two periodicities of responding were observed: a short periodicity of $5-10 \mathrm{~s}$ on the RI 60 -s schedule and a longer periodicity of $20-50 \mathrm{~s}$ that occurred on both RI 60-s and RI 120-s schedules.

Predicting the occurrence and spacing of periodic behavior could prove to be quite challenging for any theory of time perception. Broadbent (1994) concluded that scalar expectancy theory (Gibbon \& Church, 1984) and the behavioral theory of time (Killeen \& Fetterman, 1988) could not account for the periodic behavior observed on RI schedules. However, the connectionist model was offered as a strong possibility. The connectionist model of timing (Church \& Broadbent, 1990, 1992) postulates that multiple internal oscillators are used to time an interval, rather than a single accumulator like the one proposed by scalar expectancy theory. Each of the oscillators cycles with a dif- ferent period that can vary from short (e.g., $0.2 \mathrm{~s}$ ) to long (e.g., $204.8 \mathrm{~s}$ ). The oscillators send information to status indicators, which store the phase of the associated oscillator. The set of oscillator phases is sent to both working and reference memory, where the phases are converted into matrices of connection weights. The decision to respond is a function of the degree of similarity between the present state of the set of oscillators on a given trial and the set of values stored in the reference memory matrix. If the similarity score exceeds some threshold value, then a high rate of responding will occur.

To apply the connectionist model to the periodic responding observed in a random environment, Broadbent (1994) conducted a computer simulation in which interfood intervals were randomly distributed with a mean of 60 or $120 \mathrm{~s}$. She discovered that the degree of similarity of the oscillator phases was not constant; rather, the similarity functions changed in a periodic fashion that was the same for both schedules. Thus, the presentation of random interfood intervals yielded schedule-independent periodic changes in the correlation of the phase angles of the multiple oscillators that could have been responsible for the observed periodicities in operant responding.

Could the connectionist model also account for the schedule-dependent cyclicity of operant responding evidenced by our pigeons? The connectionist model may explain the quadruple peaks observed in Experiment 5 and the double peaks observed in Experiments 1-4 if one assumes that the 1:4 FI:PI duration ratio might have activated a particular set of oscillators that would yield periodic responding.

Intriguing support for this proposition comes from a recent project by Wearden and Doherty (1995), who conducted several computer simulations of the connectionist model. They used 11 oscillators to time a 40-s FI paired with a 120 -s PI $(40+/ 120-)$. The range and particular values of the oscillators varied. Of particular interest were the results of one simulation with a tightly distributed set of oscillators (ranging from 15 to $65 \mathrm{~s}$ in 5 -s increments), where two peaks in responding were produced: one at the time of the FI $(t)$ and the second at $2 t$.

Although our second peak always occurred at $3 t$, the simulated results of Wearden and Doherty do indicate that, given the right set of oscillators, two peaks in responding during PI trials can be produced. Of course, their choice of a 1:3 FI:PI ratio does not correspond with the 1:4 ratio that we found to be especially effective in producing the double peaks. This disparity notwithstanding, our empirical data combined with their simulations strongly encourage further testing and development of the connectionist model.

In addition to the need to account for the presence of double peaks when the FI:PI duration ratio is 1:4 but not when it is $1: 8$, two additional aspects of the data must be accounted for by any theory of time perception. First, both peaks exhibited a scalar property. In Experiment 2, when pigeons were trained with $15+/ 60-, 30+/ 120-$, and $60+/$ $240-$ schedules, the three groups produced two peaks that superposed when plotted on a relative time scale (see Figure 4). Superposition of a single peak is readily accounted for 
by all three theories of time perception, and extending the accounts to a second peak may not prove too difficult. A second and more challenging property of the data is that the spread of the second peak (in all conditions where a second peak occurred) was nearly identical to the spread of the first peak; this can be seen most readily in Figure 4 . For example, in the $30+/ 120$ - condition, the first peak occurred near $30 \mathrm{~s}$ and had a spread of about $30 \mathrm{~s}$, and the second peak occurred near $90 \mathrm{~s}$ and had a spread of about $30 \mathrm{~s}$ (see Figure 3, left column). The fact that the spread of the second peak is nearly identical to the spread of the first peak is intriguing because the second peak occurred at $90 \mathrm{~s}$. One of the most basic facts of time perception is that the spread of the peak is a constant proportion of the time of the peak (e.g., Cheng \& Roberts, 1991; Church \& Broadbent, 1990). So, if a peak occurs at $90 \mathrm{~s}$, then its spread should be three times as large as the spread of a peak at $30 \mathrm{~s}$. This fact of time perception raises the question of what the pigeons are actually timing at $90 \mathrm{~s}$ (or, more generally, $3 \mathrm{t}$ ).

Two obvious possibilities exist: (a) The pigeons are timing $90 \mathrm{~s}$, but with a variance that is one third of what it should be; or (b) the pigeons are timing $30 \mathrm{~s}$ with a proper variance. Because there are no known instances of unscalar variance around a mean, the first possibility seems unlikely. So perhaps the pigeons timed $30 \mathrm{~s}$ twice, once at $30 \mathrm{~s}$ and again at $90 \mathrm{~s}$. In any event, the similarity of the spreads of the two peaks appears to be a key property of the data that must be accounted for by any theory of time perception. Whether or not the connectionist model (or any other theory) will be able to predict two peaks with equal spreads at the appropriate times is uncertain, but doing so will surely require some added assumptions.

Finally, it is entirely possible that FI:PI ratios other than 1:4 might engender double-peaked response distributions. The present set of experiments tested only a 1:8 ratio as an alternative to the 1:4 ratio. Clearly, further investigations will be required to uncover the range of parameters that would support two or more peaks in responding. If other FI:PI ratios do support multiple peaks, then some factor common to the various ratios could provide important clues to the underlying mechanisms.

\section{References}

Broadbent, H. (1994). Periodic behavior in a random environment. Journal of Experimental Psychology: Animal Behavior Processes, 20, 156-157.

Catania, A. C. (1970). Reinforcement schedules and psychophysical judgments: A study of some temporal properties of behavior. In W. N. Schoenfeld (Ed.), The theory of reinforcement schedules (pp. 1-42). New York: Appleton-Century-Crofts.

Catania, A. C., \& Reynolds, G. S. (1968). A quantitative analysis of the responding maintained by interval schedules of reinforce- ment. Journal of the Experimental Analysis of Behavior, 11. $327-383$

Cheng, K., \& Roberts, W. A. (1989). Timing multimodal events in pigeons. Journal of the Experimental Analysis of Behavior, 52. 363-376.

Cheng, K., \& Roberts, W. A. (1991). Three psychophysical principles of timing in pigeons. Learning and Motivation. 22, 112 128.

Cheng, K., \& Westwood, R. (1993). Analysis of single trials in pigeons' timing performance. Journal of Experimental Psychology: Animal Behavior Processes, 19, 56-67.

Cheng, K., Westwood, R., \& Crystal, J. D. (1993). Memory variance in the peak procedure of timing in pigeons. Journal of Experimental Psychology: Animal Behavior Processes, 19, 6876.

Church, R. M., \& Broadbent, H. (1990). Alternative representations of time, number, and rate. Cognition, 37, 55-81.

Church, R. M., \& Broadbent, H. (1992). A connectionist model of timing. In M. L. Commons, S. Grossberg, \& J. E. R. Staddon (Eds.), Neural network models of conditioning and action (pp. 225-240). Hillsdale, NJ: Erlbaum.

Church, R. M., Meck, W. H., \& Gibbon, J. (1994). Application of scalar timing theory to individual trials. Journal of Experimental Psychology: Animal Behavior Processes, 20, 135-155.

Church, R. M., Miller, K. D., Meck, W. H., \& Gibbon, J. (1991). Symmetrical and asymmetrical sources of variance in temporal generalization. Animal Learning and Behavior, 19, 207-214.

Gibbon, J., \& Church, R. M. (1984). Sources of variance in an information processing theory of timing. In H. L. Roitblat, T. G. Bever, \& H. S. Terrace (Eds.), Animal cognition (pp. 465-488). Hillsdale, NJ: Erlbaum.

Killeen, P. R., \& Fetterman, J. G. (1988). A behavioral theory of timing. Psychological Review, 95, 274-295.

Leak, T. M., \& Gibbon. J. (1995). Simultaneous timing of multiple intervals: Implications of the scalar property. Joumal of Experimental Psychology: Animal Behavior Processes, 21, 3-19.

Roberts, S. (1981). Isolation of an internal clock. Journal of Experimental Psychology: Animal Behavior Processes, 7. 242268.

Roberts, W. A., Cheng, K., \& Cohen, J. S. (1989). Timing light and tone signals in pigeons. Journal of Experimental Psychology: Animal Behavior Processes, 15, 23-35.

Tatham, T. A., \& Zurn, K. R. (1989). The Med-PC experimental apparatus programming system. Behavioral Research Method, Instruments, and Computers, 21, 294-302.

Ulrich, S. (1993). Discrimination and generalization along the temporal dimension using the peak procedure in pigeons. Un. published honors thesis, University of Iowa.

Wearden, J. H., \& Doherty, M. F. (1995). Exploring and developing a connectionist model of animal timing: Peak procedure and fixed-interval simulations. Journal of Experimental Psychology: Animal Behavior Processes, 21, 99-115.

Received January 16, 1996 Revision received May 21, 1996 Accepted June 3, 1996 